\title{
Entomofauna associada a povoamentos de teca localizados no sul do Estado do Espírito Santo
}

\author{
Juarez Benigno Paes ${ }^{1}$, Pedro Lício Loiola², Winy Agnolette Capelini', Lorenzo Lube dos Santos ${ }^{3}$, Hugo José Gonçalves dos \\ Santos Junior ${ }^{4}$

\begin{abstract}
'Universidade Federal do Espírito Santo, Dpto. de Ciências Florestais e da Madeira, Av. Gov. Lindemberg, 316, CP 16, CEP 29550-000, Jeronimo Monteiro, ES, Brasil 2Universidade Federal do Paraná, Av. Prefeito Lothário Meissner, 632, Jardim Botânico, CEP 80210-170, Curitiba, PR, Brasil

${ }^{3}$ Universidade Federal do Espírito Santo, Av. Fernando Ferrari, 514 - CT I, Goiabeiras, CEP 29060-970, Vitória, ES, Brasil

${ }^{4}$ Universidade Federal do Espírito Santo, Alto Universitário, Guararema, CP 16, CEP 25500-000, Alegre, ES, Brasil
\end{abstract}

*Autor correspondente:

jbp2@uol.com.br

Termos para indexação:

Reflorestamento

Desbastes

Insetos xilófagos

Coleópteros

Index terms:

Reforestation

Loopings

Xylophagous insects

Coleopters

Histórico do artigo:

Recebido em 19/03/2014

Aprovado em 30/05/2014

Publicado em 07/07/2014

doi: 10.4336/2014.pfb.34.78.675
Resumo - Florestas homogêneas são susceptíveis à ocorrência de surtos populacionais de pragas florestais. Dentre elas, os besouros são considerados importantes economicamente, não apenas pelos danos causados ao povoamento, mas principalmente pela dificuldade de controle. Este trabalho objetivou realizar um levantamento populacional de insetos, principalmente de xilófagos, em povoamentos florestais de Tectona grandis. Foram instaladas, de forma aleatória, 20 armadilhas etanólicas e 30 amostras de madeira de teca em dois povoamentos localizados nos Municípios de Alegre e Cachoeiro de Itapemirim, localizados no sul do Estado do Espírito Santo. Decorridos 18 meses (janeiro de 2011 a julho de 2012), foram coletados insetos adultos, pupas e larvas nas galerias existentes nas amostras de madeira. As coletas dos insetos adultos foram realizadas mensalmente nas armadilhas etanólicas. Durante o período de agosto de 2011 a maio de 2012 foram capturados, nas armadilhas, 742 coleópteros, pertencentes às famílias Bostrichidae e Cerambycidae e subfamília Scolytinae além de indivíduos de famílias que não são xilófagas como Chrysomelidae, Curculionidae, Elateridae, Lagriidae, Lampyridae, Scarabaeidae e Tenebrionidae. A maior incidência de insetos com características xilófagas, e uma maior diversidade de famílias de coleópteros foi obtida no povoamento localizado no Município de Alegre.

\section{Entomofauna associated to stands of teak (Tectona grandis) located in the south of Espírito Santo State, Brazil}

\begin{abstract}
Homogeneous forests are susceptive to the occurrence of population's boom of forest pests. Among them, the beetles are considered important economically, not only for the actual damages to the stand, but mainly for the difficulty of control. This work aimed to carry out a population survey of insects, mainly of xylophagous, in stands of Tectona grandis. Twenty ethanolic traps and 30 wood samples of teak were installed in two stands in the municipalities of Alegre and Cachoeiro de Itapemirim, located in the south of Espírito Santo State, Brazil. After 18 months (January of 2011 to July of 2012) adult insects, pupas and larvae in the existing galleries in wood samples were collected. The collections of the adult insects were carried out monthly in the ethanolic traps. From August of 2011 to May of 2012, it were collected 742 coleopters in the traps, from the families Bostrichidae and Cerambycidae and subfamily Scolytinae, beyond non xylophagous individuals from the families Chrysomelidae, Curculionidae, Elateridae, Lagriidae, Lampyridae, Scarabaeidae and Tenebrionidae. The highest incidence of insects with xylophagous characteristics and a higher diversity of families of coleopters were observed in Alegre municipality.
\end{abstract}




\section{Introdução}

Tectona grandis é uma espécie nativa das florestas tropicais da Índia, Mianmar, Tailândia e Laos, localizadas no sudeste asiático. As áreas de ocorrência natural possuem uma grande variação climática, indicando uma adaptação da espécie a diferentes locais. Estudos informam que as condições ideais para o crescimento da espécie são o clima tropical úmido, caracterizado por verão chuvoso e inverno seco, precipitação anual entre $1.200 \mathrm{~mm}$ e $2.500 \mathrm{~mm}$, déficit hídrico de três a cinco meses e temperatura média anual acima de $22{ }^{\circ} \mathrm{C}$ (Lamprecht, 1990; White, 1991; Figueiredo, 2001; Vieira et al., 2002; Macedo et al., 2005; Motta, 2011).

No Brasil, a espécie tem sido uma boa oportunidade de investimento, face à adaptação da cultura às condições edafoclimáticas em várias regiões. De acordo com a Associação Brasileira de Produtores de Florestas Plantadas - ABRAF (Anuário..., 2012), a área total de plantios desta espécie no Brasil em 2011 era de 67.329 ha, distribuídos entre os Estados do Acre, Amapá, Mato Grosso do Sul, Paraná, Rondônia, São Paulo, Tocantins e, principalmente, Mato Grosso e Pará.

Segundo Cotta (2010), a busca por espécies florestais com potencial para produtividade de madeira é crescente, assim como a necessidade de se trabalhar com segurança quanto às maiores produtividades e menores custos. Portanto, considerando também a importância do setor florestal para o Estado do Espírito Santo, é relevante a busca por informações técnicas coerentes na área florestal, dando prioridade às espécies que apresentem boas condições de adaptação e de produção madeireira para a implantação de povoamentos florestais.

No entanto, plantios homogêneos de espécies florestais são susceptíveis à ocorrência de surtos populacionais de pragas. Os coleópteros são considerados importantes economicamente, não apenas pelos danos causados ao povoamento, mas, principalmente, pela dificuldade de controle (Paes et al., 2012).

Os coleópteros possuem ainda grande facilidade de adaptação a diferentes ambientes florestais. Desta forma, a prevenção constitui no melhor método de proteção às florestas homogêneas quanto à ocorrência de surtos populacionais destes insetos.

As determinações das tendências, ciclos, sazonalidades e outras características deste grupo de insetos são de elevada importância no monitoramento da dinâmica de suas populações, podendo fornecer informações importantes para o desenvolvimento de novas técnicas em programas de manejo integrado de pragas, principalmente em plantios de Tectona grandis.

Silveira Neto et al. (1976) afirmaram que o levantamento de insetos é de fundamental importância para estudos ecológicos, pois é praticamente impossível contar todos os insetos de um habitat, sendo tais estudos realizados mediante estimativas de população por meio de amostragem.

No Brasil, vários estudos com coleópteros são realizados por meio de levantamentos populacionais que, por vezes, são correlacionados a dados climáticos e de vegetação, com ou sem a aplicação de índices faunísticos. São utilizadas armadilhas de impacto, que podem ser do tipo luminosa ou com atrativo, sendo a mais comum com etanol (Carvalho et al., 1996; Dall'oglio \& Peres Filho, 1997).

As armadilhas etanólicas têm fornecido ótimos resultados para o conhecimento e controle de diversas espécies de coleópteros que ocorrem associados aos danos em madeiras. São muitos os levantamentos que confirmaram a eficiência destas armadilhas na coleta de espécies das famílias Bostrichidae e Cerambycidae e das subfamílias Platypodinae e Scolytinae, como demonstrado por Peres Filho (2006); Delgado et al. (2008); Trevisan et al. (2008); Souza et al. (2009) e Paes et al. (2012).

Este trabalho teve como objetivo realizar um levantamento populacional da ocorrência de insetos xilófagos em povoamentos florestais de Tectona grandis localizados no sul do Estado do Espírito Santo.

\section{Material e métodos}

\section{Local e características dos povoamentos}

Foram selecionados dois povoamentos de teca (Tectona grandis L.f), um localizado em Santa Angélica (Município de Alegre), com 1,0 ha e o outro na divisa dos Municípios de Cachoeiro de Itapemirim e Jerônimo Monteiro, com 1,5 ha, no sul do Espírito Santo. Os povoamentos foram selecionados em função da idade (aproximadamente cinco anos) e localização. Os povoamentos estavam em idade próxima a do período de desbaste (Paes et al., 2012).

\section{Monitoramento da incidência de coleópteros nos povoamentos}

Inicialmente foi realizado um levantamento exploratório para verificar o estado fitossanitário das plantas e sorteadas as árvores para a instalação das armadilhas para a captura dos coleópteros. 
Foram instaladas no tronco das árvores armadilhas semelhantes às empregadas por Bossoes (2011) na posição correspontende ao diâmetro à altura do peito - DAP (1,30 m do solo). Para o monitoramento de coleópteros xilófagos associados à madeira de teca, empregaram-se amostras de madeira, com diâmetro de $10 \mathrm{~cm}$ a $12 \mathrm{~cm}$ e comprimento de $15 \mathrm{~cm}$, provenientes de duas árvores jovens destinadas ao desbaste e mantidas no ecossistema florestal. As amostras foram seccionadas longitudinalmente no sentido do comprimento, dando origem a duas amostras semi roliças, tendo um lado com casca e o outro (interno) sem a casca, a fim de verificar o efeito da casca na atração dos insetos.

As amostras de madeira foram distribuídas pelo povoamento em um delineamento experimental inteiramente casualizado, em duas posições na árvore, sendo uma na base $(0,30 \mathrm{~m}$ do solo) e a outra no DAP. As amostras foram compostas por 15 repetições para cada altura na árvore e local de estudo, sendo fixadas nas árvores em janeiro de 2011, com arame 18, e retiradas para análise após 18 meses.

As amostras de madeira foram instaladas nas mesmas árvores em que foram dispostas as armadilhas para a captura de insetos adultos, conforme descrito por Paes et al (2012). Neste caso, a captura ocorreu mensalmente, no período de agosto de 2011 a maio de 2012, compreendendo os meses com maiores diferenças de temperatura, precipitação pluviométrica, umidade relativa, fotoperiodismo e vento para a região de estudo.

\section{Análise da incidência de coleópteros e avaliação de danos}

As amostras de madeira distribuídas nos povoamentos foram acondicionadas em sacos plásticos e conduzidas ao Laboratório de Biodeterioração da Madeira da Universidade Federal do Espírito Santo (UFES), localizado em Jerônimo Monteiro, ES, onde foram seccionadas com o emprego de ferramentas manuais (faca e martelo), para a retirada dos insetos que se instalaram nas mesmas. Também foi feita a avaliação dos danos causados nas amostras decorrentes do desenvolvimento de galerias na madeira.

Os insetos adultos coletados nas armadilhas etanólicas e nas amostras de madeira, bem como as pupas e larvas, foram armazenados em etanol $80 \%$ e classificados em ordem e família, por comparação com o material da Coleção Entomológica do Laboratório de Entomologia da UFES, em Alegre, ES.

\section{Resultados e discussão}

Durante o período de agosto de 2011 a maio de 2012, foram capturados, nas armadilhas etanólicas, 742 insetos da ordem Coleoptera, distribuídos nas famílias Bostrichidae, Cerambycidae, Chrysomelidae, Curculionidae, Elateridae, Lagriidae, Lampyridae, Scarabaeidae e Tenebrionidae e subfamília Scolytinae (Tabela 1). Dentre os insetos das famílias Bostrichidae e Cerambycidae, estão aqueles que são xilófagos e os da subfamília Scolytinae, xilomicetófagos, por se alimentarem de fungos que cultivam na madeira. As demais famílias podem atacar folhas, botões florais, frutos e sementes, com a possibilidade de se tornarem pragas florestais, caso haja um desequilíbrio ecológico.

Além dos coleópteros, foram capturados 339 insetos correspondentes a outras ordens, sendo as com maior frequência Himenoptera, Diptera e Blattaria.

Foram coletados $55,3 \%$ dos indivíduos no povoamento situado em Santa Angélica, e no povoamento situado nas proximidades de Cachoeiro de Itapemirim, 44,7\%, em um período de 10 meses de coleta. Esses resultados indicam um equilíbrio entre as quantidades de insetos capturados, quando comparados aos valores obtidos por Paes et al. (2012) para as coletas realizadas entre janeiro a abril de 2011, em que foram capturados mais de $86 \%$ dos insetos no povoamento localizado em Santa Angélica.

Observa-se na Tabela 1 que $28,3 \%$ dos insetos coletados em Santa Angélica eram de famílias de coleópteros com representantes xilófagos, enquanto em Cachoeiro de Itapemirim, as famílias de xilófagos representaram 17,5\% do total. Indivíduos das famílias Cerambycidae e Bostrichidae e da subfamília Scolytinae, segundo Peres Filho et al. (2006) e Paes et al. (2012) são capazes de atacar a madeira de teca provenientes de primeiro e segundo desbastes, quando mantidas no ecossistema florestal ou quando armazenadas em condições propícias para o desenvolvimento dos insetos, por período suficiente para que ocorra a infestação e ataque à madeira.

A menor diversidade de insetos no povoamento localizado em Cachoeiro de Itapamirim, em relação ao de Santa Angélica, pode estar associada à prática agrícola realizada nas duas propriedades. Em Santa Angélica, o povoamento está localizado próximo a um fragmento florestal, enquanto em Cachoeiro de Itapemirim, o povoamento está próximo a uma área de pastagem. 
Tabela 1. Abundância absoluta e relativa de indivíduos das famílias de coleópteros associados ao povoamento de Tectona grandis, coletados com armadilhas etanólicas.

\begin{tabular}{lcccc}
\hline \multirow{2}{*}{$\begin{array}{l}\text { Família/ } \\
\text { Subfamília }\end{array}$} & \multicolumn{2}{c}{ Santa Angélica } & \multicolumn{2}{c}{ Cachoeiro de Itapemirim } \\
\cline { 2 - 5 } & Absundância & \multicolumn{2}{c}{ Abundância } \\
\hline Scarabaeidae & 133 & Relativa (\%) & Absoluta & Relativa (\%) \\
\hline Bostrichidae & 69 & 32,4 & 75 & 22,7 \\
Cerambycidae & 25 & 16,8 & 38 & 11,5 \\
Scolytinae & 23 & 5,9 & 20 & 6,0 \\
Elateridae & 4 & 5,6 & 0 & 0,0 \\
Lagriidae & 4 & 1,0 & 0 & 0,0 \\
Lampyridae & 4 & 1,0 & 0 & 0,0 \\
Chrysomelidae & 2 & 1,0 & 0 & 0,0 \\
Tenebrionidae & 2 & 0,5 & 0 & 0,0 \\
Curculinidae & 1 & 0,5 & 3 & 0,9 \\
Outros & 144 & 0,2 & 0 & 0,0 \\
\hline Total & 411 & 35,1 & 195 & 58,9 \\
\hline
\end{tabular}

O povoamento localizado em Cachoeiro de Itapemirim já havia passado por um desbaste, sendo a madeira deixada no povoamento, o que resultou em ataque por insetos xilófagos. Isto ocorreu provavelmente em decorrência da emissão de voláteis emanados pela casca, o que causa a atração e infestação de insetos na madeira (Zanuncio et al.,1993, Peres Filho et al., 2006).

Os coleópteros da subfamília Scolytinae, além de perfurarem a madeira, atuam como vetores de fungos que causam coloração escura, depreciando as madeiras claras (Trevisan et al., 2008), como o alburno de teca, inviabilizando sua utilização para finalidades nobres, como móveis, pisos e lambris.

Nota-se que as famílias Bostrichidae e Scarabaeidae foram aquelas de maior incidência no povoamento localizado em Santa Angélica, correspondendo a 16,8 e 32,4\%, respectivamente, da abundância relativa (Tabela $1 \mathrm{e}$ Figura 1), enquanto as famílias Cerambycidae e subfamília Scolytinae correspondem a 5,9 e 5,6\%, respectivamente. Esta superioridade pode ser justificada, uma vez que, além de serem as famílias mais abundantes da ordem Coleoptera no ambiente florestal, possuindo maior atividade na área do experimento em todo o período estudado, são também aquelas que possuem a maior especificidade ao etanol. Esta proporção de insetos coletados ressalta a importância da família Bostrichidae na deterioração da madeira armazenada no ambiente florestal.

Os indivíduos pertencentes às famílias Chrysomelidae, Curculionidae, Elateridae, Lagriidae, Lampyridae e
Tenebrionidae não foram plotados na Figura 1 em função destes corresponderem a menos de $1 \%$ da abundância relativa de ocorrência durante os 10 meses de coleta.

Assim como o ocorrido para o povoamento localizado em Alegre, ES, os insetos das famílias de Bostrichidae e Scarabaeidae foram aqueles de maior ocorrência no povoamento instalado no Município de Cachoeiro de Itapemirim (Tabela 1 e Figura 2), correspondendo a $11,5 \%$ e $22,7 \%$, respectivamente, da abundância relativa. Enquanto as famílias de Cerambycidae e Terebrionidae corresponderam a 6,0 e $0,9 \%$, respectivamente.

A abundância de insetos da família Scarabaeidae pode estar relacionada às práticas agropecuárias realizadas em ambas as localidades onde os experimentos foram conduzidos, pois, segundo Rodrigues \& Marchini (1998), indivíduos da família Scarabaeidae são importantes agentes de remoção de massas fecais em áreas de pastagens.

Em levantamentos para verificar a flutuação populacional das espécies pertencentes à família dos coleópteros deve-se atentar para os seus ciclos reprodutivos e a sua abundância (Morales et al., 1999; Oliveira et al., 2001). As condições climáticas do local podem ter relação com a flutuação populacional dos insetos. Com o aumento da temperatura, nos dias mais quentes, ocorre maior movimentação e dispersão dos insetos. Além disso, a umidade pode aumentar a frequência da batida das asas e a velocidade de voo de algumas espécies de Scolytinae, conforme citado por Atkinson (1985). 


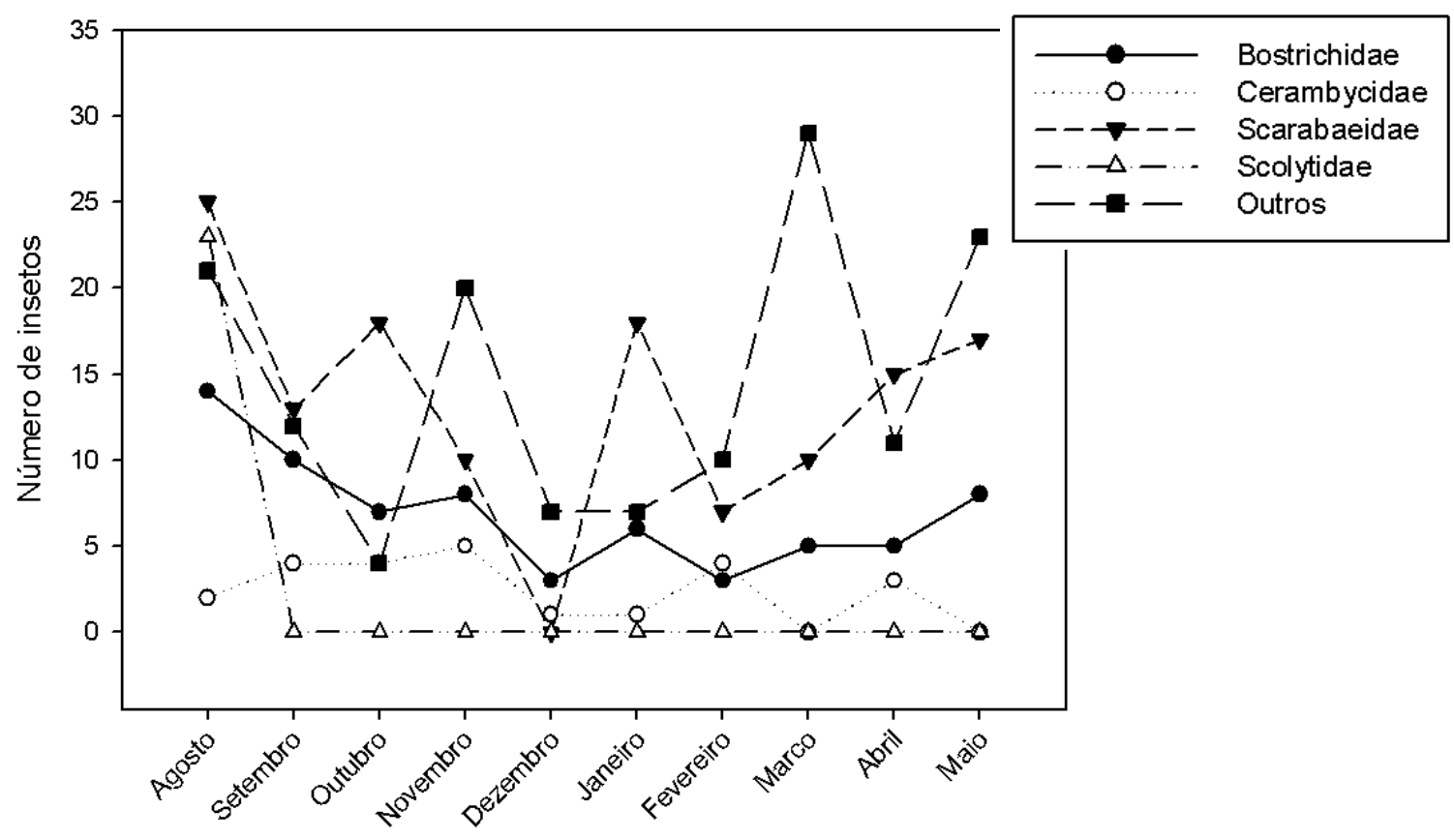

Mês de coleta

Figura 1. Flutuação populacional de coleópteros coletados em armadilhas etanólicas no povoamento de Tectona grandis localizado em Santa Angélica, Alegre, ES.

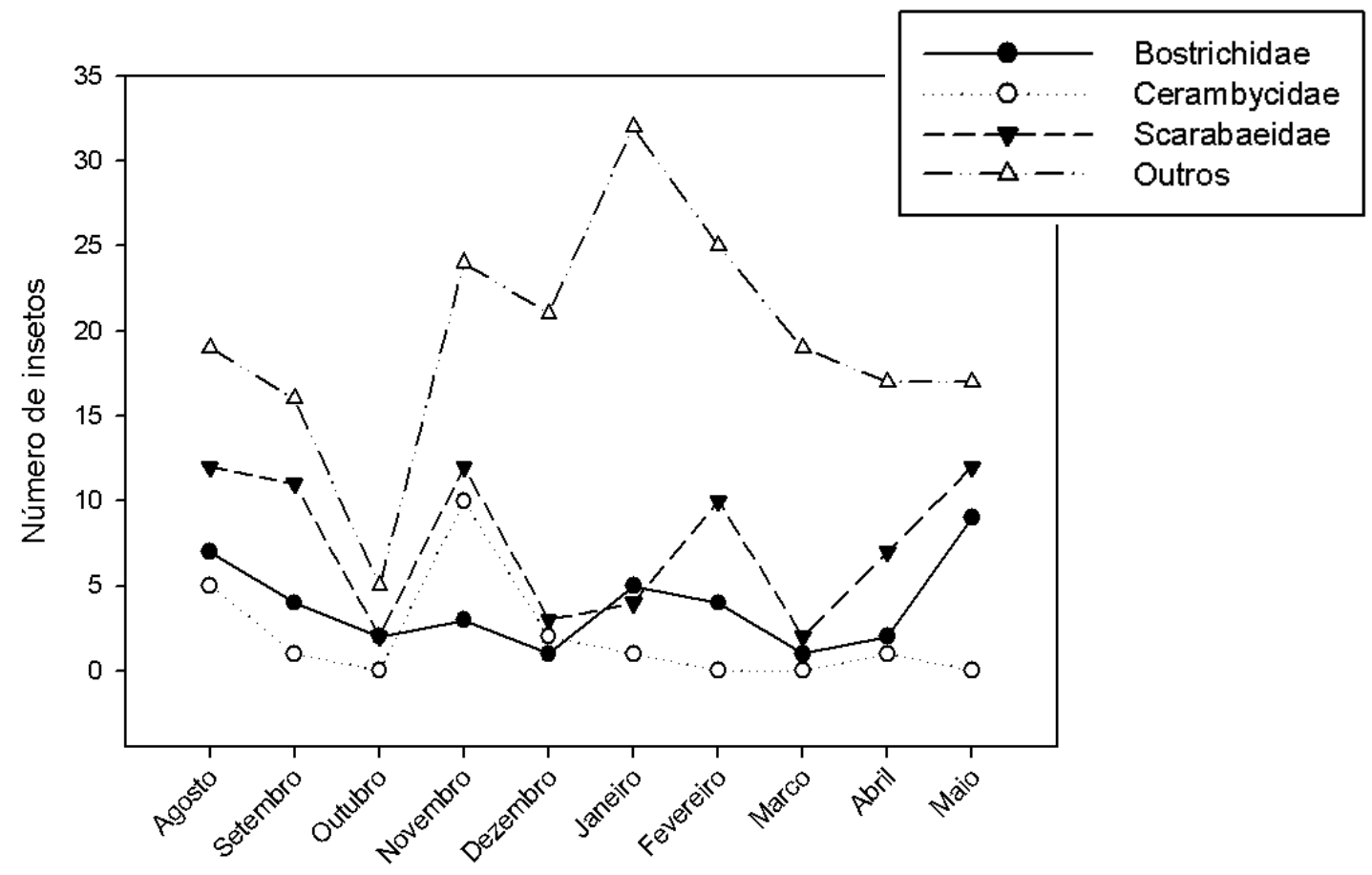

Mês de coleta

Figura 2. Flutuação populacional de coleópteros coletados em armadilhas etanólicas no povoamento de Tectona grandis localizado no Município de Cachoeiro de Itapemirim, ES. 
A quantidade de insetos coletados (Tabela 2) revelou que as amostras de madeira fixadas no DAP das árvores, foram as mais danificadas, correspondendo a $64,0 \% \mathrm{em}$ Santa Angélica e 58,1\% em Cachoeiro de Itapemirim, com resultados superiores quando comparadas às amostras dispostas na base das árvores ( $0,30 \mathrm{~m}$ do solo). Os insetos da ordem Isoptera (térmitas ou cupins) corresponderam a $64,2 \%$ e 35,8\% eram da ordem Hymenoptera (formigas), que, por não serem xilófagas, poderiam estar usando as galerias escavadas na madeira para abrigo.

A face com casca das amostras de madeira foram as mais atacadas, uma vez que os coleópteros encontram maior facilidade de oviposição na madeira com casca e também as larvas encontram condições favoráveis ao seu desenvolvimento inicial na interface cascamadeira. As amostras sem casca, por não disporem de condições adequadas para a oviposição e manutenção das larvas nos estágios iniciais de desenvolvimento e pela perda de umidade mais acelerada que as amostras com casca tornaram-se menos atrativas para algumas espécies de coleópteros (Costa et al., 1988).

De acordo com Dorval (2002) e Dorval et al. (2004), os danos causados por coleópteros em toras de Eucalyptus spp. iniciam-se a partir dos 30 dias de exposição no campo, atingindo nível máximo de infestação no período de 150 a 180 dias.

Diferentes fatores podem resultar em períodos críticos de ataque diferentes. Abreu \& Bandeira (1992) registraram ataques intensos de Platypus parallelus
(Platypodinae) e Xyleborus affinis (Scolytinae) em discos de tauari (Eschweilera odora) e de mandioqueira (Qualea brevipedicellata), aos 60 dias de exposição, no Município de Presidente Figueiredo, Estado do Amazonas.

A intensidade de ataque depende do tamanho da população de coleópteros no ecossistema florestal e das condições de temperatura para acelerar o processo de fermentação anaeróbica de carboidratos da madeira durante sua deterioração, determinando maiores ou menores danos causados à madeira recém-cortada (Moura, 2007).

De acordo com Marques et al. (1990), 30 dias de permanência de amostras de madeira, com casca, recém-cortada no ecossistema florestal pode acarretar uma infestação insignificante. Esta baixa infestação é supostamente atribuída às condições desfavoráveis para fermentação rápida e aos baixos níveis populacionais das espécies de coleópteros. No entanto, a permanência das amostras no campo resulta em aumento da infestação.

Além dos insetos adultos coletados nas amostras de madeira (Tabela 2), foram também extraídas pupas e larvas (Tabela 3). No povoamento em Cachoeiro de Itapemirim foram coletadas pupas e larvas pertencentes à família Cerambycidae, que são xilófagas, e da família Scarabaeidae, que, por não serem xilófagas, podem ter sido depositadas entre a madeira e a casca das amostras. Tais insetos se alimentam de matéria em decomposição, como a casca das amostras de madeira fixadas com arame e mantidas próximas ao solo.

Tabela 2. Quantidade de insetos coletados das ordens Hymenoptera e Isoptera nas amostras de madeiras mantidas no ecossistema florestal nas duas localidades amostradas, para cada posição no tronco.

\begin{tabular}{|c|c|c|c|}
\hline \multirow{2}{*}{ Período de coleta } & \multicolumn{3}{|c|}{ Santa Angélica } \\
\hline & Posição no tronco & Ordem & Quantidade \\
\hline \multirow{4}{*}{18 meses } & \multirow{2}{*}{$0,30 \mathrm{~m}$} & Isoptera & 30 \\
\hline & & Hymenoptera & 15 \\
\hline & \multirow{2}{*}{$1,30 \mathrm{~m}$} & Isoptera & 50 \\
\hline & & Hymenoptera & 30 \\
\hline Total & & & 125 \\
\hline \multirow{2}{*}{ Período de coleta } & \multicolumn{3}{|c|}{ Cachoeiro de Itapemirim } \\
\hline & Posição no tronco & Ordem & Quantidade \\
\hline \multirow{4}{*}{18 meses } & \multirow{2}{*}{$0,30 \mathrm{~m}$} & Isoptera & 24 \\
\hline & & Hymenoptera & 15 \\
\hline & \multirow{2}{*}{$1,30 \mathrm{~m}$} & Isoptera & 36 \\
\hline & & Hymenoptera & 18 \\
\hline Total & & & 93 \\
\hline
\end{tabular}


Tabela 3. Larvas e pupas das famílias Scarabaeidae e Cerambycidae coletadas nas amostras de madeiras mantidas no ecossistema florestal das duas localidades amostradas para cada posição no tronco.

\begin{tabular}{|c|c|c|c|c|}
\hline \multirow{2}{*}{ Período de coleta } & \multicolumn{4}{|c|}{ Santa Angélica } \\
\hline & Posição no tronco & Ordem & Família & Quantidade \\
\hline \multirow{4}{*}{18 meses } & \multirow{2}{*}{$0,30 \mathrm{~m}$} & \multirow{4}{*}{ Coleoptera } & Scarabaeidae & 1 \\
\hline & & & Cerambycidae & 2 \\
\hline & \multirow{2}{*}{$1,30 \mathrm{~m}$} & & Cerambycidae & 2 \\
\hline & & & Scarabaeidae & 2 \\
\hline Total & & & & 7 \\
\hline \multirow{2}{*}{ Período de coleta } & \multicolumn{4}{|c|}{ Cachoeiro de Itapemirim } \\
\hline & Posição no tronco & Ordem & Família & Quantidade \\
\hline \multirow{3}{*}{18 meses } & \multirow{2}{*}{$0,30 \mathrm{~m}$} & \multirow{3}{*}{ Coleoptera } & Cerambycidae & 1 \\
\hline & & & Scarabaeidae & 8 \\
\hline & $1,30 \mathrm{~m}$ & & Cerambycidae & 2 \\
\hline Total & & & & 11 \\
\hline
\end{tabular}

Foram observados orifícios e galerias de insetos, com mais frequência, no lado das amostras em que foi mantida a casca. No lado sem a casca foram observados orifícios de insetos apenas nos topos das mesmas e na região da medula.

Segundo Nair (2007), além do surgimento de orifícios na madeira, os ataques são caracterizados pela quantidade de serragem expelida através deles, proveniente da atividade larval. As galerias podem ser circulares, estreitas e estarem limpas ou repletas de serragem compactada.

O levantamento populacional e o controle biológico destes indivíduos devem ser realizados por causa dos danos ocasionados à madeira, que se constituem em orifícios e galerias escavadas pelas larvas e na presença de insetos adultos na região do alburno (Peres Filho et al., 2006; Moura, 2007), que podem inutilizar a madeira para as finalidades a que se destina e impedir sua entrada em outros países fora da região de ocorrência do inseto.

\section{Conclusões}

No povoamento localizado em Santa Angélica, Município de Alegre, ES, é verificada maior incidência de insetos com características xilófagas e também maior diversidade de famílias de coleópteros, quando se compara ao localizado no Município de Cachoeiro de Itapemirim, ES.

A família de Coleoptera com representantes xilófagos mais frequentes nos povoamentos de teca para os dois locais amostrados é a Bostrichidae.
Não foram constatados indivíduos adultos pertencentes à ordem coleóptera nas amostras de madeira mantidas nos povoamentos, mas foram observados orifícios e galerias abertas pelas larvas e pelos insetos adultos pertencentes a essa ordem.

\section{Agradecimentos}

À Fundação de Amparo a Pesquisa do Espírito Santo (FAPES), pela Bolsa de Iniciação Científica concedida, e à Raquel Fernandes Zorzanelli, Monitora da Disciplina de Entomologia Básica do Laboratório de Entomologia, Centro de Ciências Agrárias, Universidade Federal do Espírito Santo, pelo auxílio na classificação dos insetos.

\section{Referências}

ANUÁRIO Estatístico da ABRAF 2012: ano base 2011. Brasília, DF: ABRAF, 2012. 145 p. Disponível em: <http://www.abraflor.org. br/estatisticas/abraf12/abraf12-br.pdf >. Acesso em: 13 mar. 2014.

ABREU, R. L. S.; BANDEIRA, A. G. Besouros xilomicetófagos economicamente importantes da região de Balbina, Estado do Amazonas. Revista Árvore, Viçosa, MG, Viçosa, MG, v.16, n. 3, p. 346-356, 1992.

ATKINSON, T. H. Los generos de la família Scolytidae (Coleoptera em México. Resumen de su taxonomía y biologia). In: SIMPOSIA NACIONALES DE PARASITOLOGIA FLORESTAL II Y III. Memoria... Mexico: Secretaria de Agricultura y Recursos Hidráulicos, 1985. p. 97-105. (Publicación especial, 46).

BOSSOES, R. R. Avaliação e adaptação de armadilhas para captura de insetos em corredor agroflorestal. 2011. 46 f. Dissertação (Mestre em Ciências - Fitossanidade e Biotecnologia Aplicada) Universidade Federal Rural do Rio de Janeiro, Seropédica. 
CARVALHO, A. G.; ROCHA, M. P.; SILVA, C. A. M.; LUNZ, A. M. Variação sazonal de Scolytidae (Coleoptera) numa comunidade de floresta natural de Seropédica, RJ. Floresta e Ambiente, Seropédica, v. 3, n. 2, p. 9-14, 1996.

COSTA, E. C.; MOURA, J. B.; MARQUES, E. N. Observação sobre madeira cortada e mantida no ecossistema florestal. Revista do Centro de Ciência Rurais, Santa Maria, RS, v. 18, n. 3/4, p. 239-247, 1988.

COTTA, T. R. Zoneamento climatológico para o cultivo de teca no Estado do Espírito Santo. 2010. 27 f. Monografia (Graduação em Engenharia Florestal) - Universidade Federal do Espírito Santo, Jerônimo Monteiro.

DALL'OGLIO, O. T.; PERES FILHO, O. Levantamento e flutuação de populacional de coleobrocas em plantios homogêneos de seringueira em Itiquira-MT. Scientia Forestalis, Piracicaba, v. 51, n. 2, p. 49-58, 1997.

DELGADO, L. G. M.; GOMES, J. E.; ARAUJO, H. B. Análise do sistema de produção de teca (Tectona grandis L.f.) no Brasil. Revista Científica Eletrônica de Engenharia Florestal, Garça, v. 1, n. 11, p. 1-6, 2008.

DORVAL, A. Levantamento populacional de coleópteros com armadilhas etanólicas em plantios de Eucalyptus spp. em uma área com vegetação de cerrado no município de Cuiabá, Estado de Mato Grosso. 2002. 141 f. Tese (Doutorado em Ciências Biológicas) - Universidade Federal do Paraná, Curitiba.

DORVAL, A.; PERES FILHO, O.; MARQUES, E. N. Levantamento de Scolytidae (Coleoptera) em plantações de Eucalyptus spp. em Cuiabá, Estado de Mato Grosso. Ciência Florestal, Santa Maria, RS, v. 14, n. 1, p. 47-58, 2004.

FIGUEIREDO, E. O. Reflorestamento com teca (Tectona grandis L.f.) no Estado do Acre. Rio Branco: Embrapa Acre, 2001. 28 p. (Embrapa Acre. Documentos, 65).

LAMPRECHT, H. Silvicultura nos trópicos: ecossistemas florestais e respectivas espécies arbóreas: possibilidades e métodos de aproveitamento sustentado. Eschborn: Deutsche Gesellschaft für Technische Zusammenarbeit (GTZ) GmbH, 1990. 343 p.

MACEDO, R. L. G.; GOMES, J. E.; VENTURIN, N.; SALGADO, B. G. V. Desenvolvimento inicial de Tectona grandis L.f. (teca) em diferentes espaçamentos no município de Paracatu, MG. Cerne, Lavras, v. 11, n. 1, p. 61-69, 2005.

MARQUES, E. N; PEDROSA-MACEDO J. H.; DIODATO, M. A. Estudio del grado de infestación por Scolytidae em madera cortada. In: IUFRO WORLD CONGRESS. 2., 1990, Toronto. Proceedings... Toronto: University of Toronto, Faculty of Forestry, 1990. p. 270-278.

MORALES, N. E.; ZANUNCIO, J. C; MARQUES, E. N.; PRATISSOLI, D.; COUTO. L. Índices populacionais de besouros Scolytidae em reflorestamento de Eucalyptus grandis W. Hill ex. Maiden no município de Antônio Dinas, Minas Gerais. Revista Árvore, Viçosa, MG, v. 23, n. 3, p. 359-363, 1999.
MOTTA, J. P. Propriedades tecnológicas da madeira de Tectona grandis L. f. proveniente do Vale do Rio Doce, Minas Gerais. 2011. 125 f. Dissertação (Mestrado em Ciências Florestais) - Universidade Federal do Espírito Santo, Jerônimo Monteiro.

MOURA, R. G. Coleobrocas (Insecta: Coleoptera) associada à madeira de Tectona grandis Linn. F (Lamiaceae). 2007. $57 \mathrm{f}$. Dissertação (Mestrado em Ciências - Silvicultura e Manejo Florestal) - Universidade de São Paulo, Escola Superior de Agricultura "Luiz de Queiroz", Piracicaba.

NAIR, K. S. S. Tropical forest insect pests: ecology, impact and management. New York: Cambridge University, 2007. 404 p.

OLIVEIRA, H. G.; ZANUNCIO, T. V.; ZANUNCIO J. C.; ZANUNCIO, Z. P. Coleópteros associados à eucaliptocultura na região de Nova Era, Minas Gerais, Brasil. Floresta e Ambiente, Seropédica, v. 8, n. 1, p. 52-60, 2001.

PAES, J. B.; SANTOS, L. L.; LOIOLA, P. L.; SANTOS JUNIOR, H. J. G.; CAPELINI, W. A. Ataque de coleópteros na madeira de teca (Tectona grandis L.f) em plantios localizados no sul do Espírito Santo. Revista Científica Eletrônica de Engenharia Florestal. Garça, v. 20, n. 1, p. 1-9, 2012.

PERES FILHO, O.; DORVALA, BERTI FILHO, E. A. Entomofauna associada à teca, Tectona grandis L.f. no Estado de Mato Grosso. Piracicaba: IPEF, 2006. 58 p.

RODRIGUES, S. R.; MARCHINI, L. C. Besouros coprófagos (Coleoptera; Scarabaeidae) coletados em piracicaba, SP. Scientia Agrícola, Piracicaba, v. 55, n. 1, p. 53-58, 1998.

SILVEIRA NETO, S.; NAKANO, O.; BARBIN, D. Manual de ecologia dos insetos. São Paulo: Agronômica Ceres, 1976. 419 p.

SOUZA, R. M.; ANJOS, N.; MOURÃO S. A. Apate terebrans (pallas) (coleoptera: Bostrychidae) atacando árvores de nim no Brasil. Neotropical Entomology, São Paulo, v. 38, n. 3, p. 437-439, 2009.

TREVISAN, H.; MARQUES, F. M. T.; CARVALHO, A. G. Degradação natural de toras de cinco espécies florestais em dois ambientes. Floresta, Curitiba, v. 38, n. 1, p. 33-41, 2008.

VIEIRA, A. H.; MARTINS, E. P.; PEQUENO, P. L. L.; LOCATELLI, M. Aspectos silviculturais da teca em Rondônia. Porto Velho: Embrapa Rondônia, 2002. 15 p. (Embrapa Rondônia. Documentos, 68).

WHITE, K. J. Teak: some aspects of research and development. Bangkok: Rapa Publications, Food and Agriculture Organization of the United Nations, 1991. $53 \mathrm{p}$.

ZANUNCIO, J. C.; BRAGANÇA, M. A. L.; LARANJEIRO, A. J. FAGUNDES, M. Coleópteros associados à eucaliptocultura nas regiões de São Mateus e Aracruz, Espírito Santo. Revista Ceres, Viçosa, MG, v. 41, n. 22, p. 584-590, 1993. 